\title{
Vacuolar ATPase depletion contributes to dysregulation of endocytosis in bloodstream forms of Trypanosoma brucei
}

Zhi-Shen Xu' ${ }^{1}$, Feng-Jun Li ${ }^{2}$, Geoff Hide ${ }^{3}$, Zhao-Rong Lun ${ }^{1,3^{*}}$ and De-Hua Lai ${ }^{{ }^{*}}$

\begin{abstract}
Background: Vacuolar $\mathrm{H}^{+}$-ATPase (V-ATPase) is a highly conserved protein complex which hydrolyzes ATP and pumps protons to acidify vacuolar vesicles. Beyond its role in $\mathrm{pH}$ maintenance, the involvement of V-ATPase in endocytosis is well documented in mammals and plants but is less clear in Trypanosoma brucei.

Methods: In this study, the subcellular localization of V-ATPase subunit B (TbVAB) of T. brucei was assessed via in situ $\mathrm{N}$-terminal YFP-tagging and immunofluorescence assays. Transgenic bloodstream forms (BSF) of T. brucei were generated which comprised either a V-ATPase subunit B (TbVAB) conditional knockout or a V-ATPase subunit A (TbVAA) knockdown. Acridine orange and BCECF-AM were employed to assess the roles of $\mathrm{V}$-ATPase in the $\mathrm{pH}$ regulation of BSF T. brucei. The endocytic activities of three markers were also characterized by flow cytometry analyses. Furthermore, trypanosomes were counted from trypanolysis treatment groups (either containing $1 \%$ or $5 \% \mathrm{NHS}$ ) and endocytosed trypanosome lytic factor (TLF) was also analyzed by an immunoblotting assay.
\end{abstract}

Results: TbVAB was found to localize to acidocalcisomes, lysosomes and probably also to endosomes of BSF of $T$. brucei and was demonstrated to be essential for cell growth. TbVAB depletion neutralized acidic organelles at 24 hours post-tetracycline depletion (hpd), meanwhile the steady state intracellular pH increased from $7.016 \pm 0.013$ to $7.422 \pm 0.058$. Trypanosomes with TbVAB depletion at $24 \mathrm{hpd}$ were found to take up more transferrin $(2.068 \pm 0.277$ fold) but less tomato lectin ( $49.31 \pm 22.57 \%$ ) by endocytosis, while no significant change was detected in dextran uptake. Similar endocytic dysregulated phenotypes were also observed in TbVAA knockdown cells. In addition, TbVAB depleted trypanosomes showed a low uptake of TLF and exhibited less sensitive to lysis in both 1\% and 5\% NHS treatments.

Conclusions: TbVAB is a key component of V-ATPase and was found to play a key function in endocytosis as well as exhibiting different effects in a receptor/cargo dependent manner in BSF of T. brucei. Besides vacuolar alkalinization, the dysregulation of endocytosis in TbVAB depleted T. brucei is considered to contribute to the reduced sensitivity to lysis by normal human serum.

Keywords: Trypanosoma brucei, Vacuolar ATPase, Apolipoprotein L1, Endocytosis, Trypanolysis

*Correspondence: Isslzr@mail.sysu.edu.cn; laidehua@mail.sysu.edu.cn ${ }^{1}$ Center for Parasitic Organisms, State Key Laboratory of Biocontrol, School of Life Sciences, and Key Laboratory of Tropical Disease Control (Sun Yat-Sen University), Ministry of Education, Sun Yat-Sen University, Guangzhou 510275, The People's Republic of China

Full list of author information is available at the end of the article

\section{Background}

Trypanosoma brucei, a unicellular haemoflagellate, the causative agent of sleeping sickness or human African trypanosomiasis, is threatening approximately 70 million people living in sub-Saharan Africa [1]. Trypanosoma brucei evades the mammalian immune system using antigenic variation in the surface coat and relying on a very

c) The Author(s) 2020. This article is licensed under a Creative Commons Attribution 4.0 International License, which permits use, sharing, adaptation, distribution and reproduction in any medium or format, as long as you give appropriate credit to the original author(s) and the source, provide a link to the Creative Commons licence, and indicate if changes were made. The images or other third party material in this article are included in the article's Creative Commons licence, unless indicated otherwise in a credit line to the material. If material is not included in the article's Creative Commons licence and your intended use is not permitted by statutory regulation or exceeds the permitted use, you will need to obtain permission directly from the copyright holder. To view a copy of this licence, visit http://creativeco mmons.org/licenses/by/4.0/. The Creative Commons Public Domain Dedication waiver (http://creativecommons.org/publicdomain/ zero/1.0/) applies to the data made available in this article, unless otherwise stated in a credit line to the data. 
efficient endocytic system that is capable of recycling the entire surface protein coat within 12 minutes [2]. It also utilizes the serum-resistance associated (SRA) protein in T. b. rhodesiense [3] or glycoprotein TgsGP in T. b. gambiense [4] to resist trypanolysis mediated by APOL1 in normal human serum (NHS). Recently, genomic-scale RNA interference screening revealed a link between NHS/APOL1-mediated trypanolysis [5, 6] and drug toxicity [7] to vacuolar $\mathrm{H}^{+}$-ATPase (V-ATPase) in T. bru$c e i$, indicating the potential physiological functions of $\mathrm{V}$-ATPase in challenging environments.

V-ATPase is a conserved and crucial protein complex found in endosomal compartments in all eukaryotes [8, 9]. This large complex contains many subunits, forming a rotary cytoplasmic $V_{1}$ moiety $\left(\mathrm{V}_{1}\right.$-ATPase, subunits $\left.\mathrm{A}_{3} \mathrm{~B}_{3} \mathrm{CDE}_{3} \mathrm{FG}_{3} \mathrm{H}\right)$ and a transmembrane Vo moiety (Vo proton channel, subunits $\mathrm{ac}_{8} \mathrm{c}^{\prime} \mathrm{c}^{\prime \prime} \mathrm{de}$ ). The concerted action of the $V_{1}$ and Vo moiety couples ATP hydrolysis with the transport of protons across membranes and defines the fundamental function of V-ATPase in cellular compartment acidification. The V-ATPase generates an electrochemical proton gradient as a driving force for numerous secondary transport activities across membranes [10]. Furthermore, V-ATPase can be coupled with other transporters, e.g. the $\mathrm{Na}^{+} / \mathrm{H}^{+}$antiporter, and contributes to intracellular $\mathrm{pH}$ homeostasis in mammalian cells [11]. Previous studies also revealed multi-physiological functions of V-ATPase in response to environmental stresses such as nutrient availability, salinity and $\mathrm{pH}$, via an assembly/disassembly mechanism [12-14]. The requirement for V-ATPase activity in secretory and endocytic trafficking was also observed in mammals and plants [15-18], providing important evidence for an extensive function of V-ATPase activity. Although V-ATPase has been well studied in various model organisms, its roles and mechanisms of action in early-branched single cell protozoans is less clear.

Bioinformatic analyses have identified all orthologues of the V-ATPase subunits in T. brucei [5] and pioneering studies indicated some important and distinctive roles of the V-ATPase in T. brucei [7]. Subunits $\alpha$ (Tb427.05.1300) and $\mathrm{d}$ (Tb927.5.550) of V-ATPase in the procyclic form (PCF) found in the insect vector of T. brucei was found localized to the lysosomes, Golgi complex and acidocalcisomes [19], indicating localization-dependent distinct roles of V-ATPase. RNAi knockdown of subunit A (TbVAA, Tb427.04.1080) and $\alpha$ blocked the acidification of lysosomes and acidocalcisomes in the PCF of $T$. brucei [20]. Treatment of the cells with bafilomycin $\mathrm{A}_{1}$, a V-ATPase inhibitor binding to subunit c [21], markedly acidified the steady-state $\mathrm{pH}_{\mathrm{i}}$ of PCF of T. brucei and decreased the $\mathrm{pH}_{\mathrm{i}}$ recovery rate [22]. The bafilomycin $\mathrm{A}_{1}$ could further disturb $\mathrm{Ca}^{2+}$ homeostasis in the PCF of $T$. brucei via a $\mathrm{Ca}^{2+} / \mathrm{H}^{+}$antiporter in a $\mathrm{pH}$ gradient-dependent manner [23]. However, for the medically important human infective bloodstream form (BSF) of T. brucei, only a few studies have been conducted. Important questions remain unanswered such as whether V-ATPase has a similar localization in the BSF as in the PCF of T. bru$c e i$ and whether V-ATPase has similar roles in endocytic trafficking in BSF of T. brucei as in other eukaryotes. Several V-ATPase subunits have been revealed to be crucial for trypanolysis by NHS/recombinant APOL1 $[5,6]$ and drug toxicity [7], and have been suggested to attribute to V-ATPase's role in vacuolar acidification [5-7]. However, studies of the roles of trypanosomal V-ATPase activity in endocytosis are preliminary [5] although it has been consistently shown to make a contribution to $\mathrm{pH}$ regulation $[5,22]$.

To better understand the functions of V-ATPase in the BSF of T. brucei, we characterized the localization of the V-ATPase subunit B (TbVAB) and investigated its function by using conditional knockout mutants (cKO) or RNAi knockdown (KD) methods. Our results reveal its multiple localizations and crucial roles affecting endocytosis in the BSF of T. brucei in a receptor/cargo dependent manner. Our findings also indicate coordination of lysosomal function with upstream endocytic activity in trypanosomes, in which V-ATPase defects may lead to a reduced sensitivity to TLF-mediated trypanolysis.

\section{Methods}

\section{Cell culture and transfection}

Trypanosoma brucei brucei cell lines Lister 427, SmOx B427 [24], SmOx PAntat1.1 and derivatives were grown in HMI-9 (for bloodstream forms) or SDM-79 (for procyclic forms) media supplemented with $10 \%$ fetal calf serum (ExCell Bio, Shanghai, China). Transfection was conducted using an Amaxa Nucleofector (Lonza, Cologne, Germany) with human T-cell Nucleofector solution [25] and transfectants were selected with blasticidin, hygromycin, neomycin, phleomycin or puromycin [26]. Cell proliferation was monitored by counting with a hemocytometer every 12 or $24 \mathrm{~h}$.

\section{Plasmid construction}

Gene-specific RNAi fragments ( 400 bp) of TbVAA (Tb427.04.1080) and TbVAB (Tb927.11.11690) were selected with RNAit (https://dag.compbio.dundee.ac. uk/RNAit/), amplified by PCR using primers shown in Additional file 1: Table S1 and cloned into p2T $7^{\mathrm{Ti}}-177$ vector [27] using the restriction enzymes indicated. Gene knockout plasmids were generated by insertion of about $500 \mathrm{bp}$ of $T b V A B$ 5' and 3' UTR into the plew90/plew13 backbone, respectively [28]. To ectopically express the N-terminal TY-tagged TbVAB, the full-length ORF was 
amplified with Q5 HF DNA polymerase (NEB, Ipswich, USA), digested with SpeI and BclI, and then cloned into the pDex577 plasmid $[29,30]$. For inducible expression of C-terminal HA-tagged Rab11 [30], the ORF was amplified (a HA-tag was introduced in the reverse primer, Additional file 1: Table S1) and cloned into the pDex577 vector. Linearized pDex577 plasmids were transfected and integrated into the trypanosomes $177 \mathrm{bp}$ telomere repeats through homologous recombination [27]. To construct the N-terminal YFP-tagged TbVAB, the 5' UTR and 5' CDS fragments were amplified and cloned into SpeI and BamHI digested pEnT6B-Y [30].

Recombinant $T b V A B$ expression and antiserum preparation To express the N-terminal His6-tagged protein, the full length of TbVAB ORF was cloned into pET-32 $\alpha(+)$, using primers shown in Additional file 1: Table S1. The resultant vectors were transformed into $E$. coli BL21 (DE3) cells (Transgen, Beijing, China) and protein expression was induced with $0.6 \mathrm{mM}$ isopropyl- $\beta$ - $D$ 1-thiogalactopyranoside (IPTG) at $37{ }^{\circ} \mathrm{C}$ for $5 \mathrm{~h}$. Cells were centrifuged at $10,000 \times g$ for $5 \mathrm{~min}$ and inclusion body proteins were extracted using ultra-sonication. The recombinant proteins were purified using Ni-NTA resin (Qiagen, Valencia, USA) following the manufacturer's protocol. Rabbits were immunized with purified proteins according to standard procedures. The antisera were stored at $-80^{\circ} \mathrm{C}$ until used.

\section{Immunoblotting}

Proteins extracted from $2.5 \times 10^{6}$ cells were separated by SDS/PAGE gel and transferred onto NC membrane (PALL, Ann Arbor, USA). The immunoblotting against specific proteins were performed using rabbit antiTbVAB (1:2000), rabbit anti-APOL1 (1:500, Proteintech Group, Chicago, USA) and mouse anti-PFR (L8C4, 1:500) [31] after blocking in TTBS with 5\% milk. The blots were incubated with horseradish peroxidase conjugated antimouse or anti-rabbit IgG $(\mathrm{H}+\mathrm{L})$ antibody (1:2000, Invitrogen, Carlsbad, USA) and visualized using the ECL substrate (Thermo Fisher Scientific, Rockford, USA). The signal intensity was quantified using Image J.

\section{Vacuolar and cellular $\mathrm{pH}$ measurement}

After $30 \mathrm{~min}$ incubation at $37^{\circ} \mathrm{C}$ with $6 \mu \mathrm{M}$ acridine orange (AO) (Sigma, St. Louis, USA), and washing with PSG, vacuolar $\mathrm{pH}$ of trypanosomes was monitored by fluorescence microscopy using the $590-650 \mathrm{~nm}$ filter channel, while DNA contents were also monitored with the 505-550 nm filter channel. The intracellular $\mathrm{pH}\left(\mathrm{pH}_{\mathrm{i}}\right)$ of trypanosomes was monitored using the cell-permeant, dual-excitation ratiometric $\mathrm{pH}$ indicator BCECF-AM (2', 7'-bis (2-carboxyethyl)-5, 6-carboxyfluorescein acetoxymethyl ester) (Beyotime, Shanghai, China) following the published protocol [22]. Briefly, cells were harvested and washed twice in buffer A $(116 \mathrm{mM} \mathrm{NaCl}, 5.4 \mathrm{mM} \mathrm{KCl}$, $0.8 \mathrm{mM} \mathrm{MgSO}_{4}, 5.5 \mathrm{mM}$ D-glucose and $50 \mathrm{mM}$ Hepes, $\mathrm{pH}$ 7.4) at $4{ }^{\circ} \mathrm{C}$ and resuspended in loading buffer (135 $\mathrm{mM} \mathrm{NaCl}, 5 \mathrm{mM} \mathrm{KCl}, 1 \mathrm{mM} \mathrm{MgSO}, 1 \mathrm{mM} \mathrm{CaCl}_{2}$, $15 \mathrm{mM}$ sucrose, $10 \mathrm{mM}$ Hepes at $\mathrm{pH} 7.4$ and $0.1 \mu \mathrm{M}$ BCECF-AM) to a final density of $1 \times 10^{8}$ cells $/ \mathrm{ml}$. After incubation on ice for $30 \mathrm{~min}$, all samples were washed twice with pre-chilled separation buffer $(40 \mathrm{mM} \mathrm{NaCl}$, $57 \mathrm{mM} \mathrm{Na} 2 \mathrm{HPO}_{4}, 3 \mathrm{mM} \mathrm{NaH} \mathrm{PO}_{4}, 10 \mathrm{mM}$-glucose at $\mathrm{pH}$ 7.4) and resuspended in the same buffer to a final density of $2 \times 10^{7}$ cells $/ \mathrm{ml}$. A total of $200 \mu \mathrm{l}$ cell suspension was transferred into a black 96-well microplate and the fluorescence was monitored at $37{ }^{\circ} \mathrm{C}$ using a thermostatically controlled SpectraMax i3x microplate fluorometer (Molecular Devices, Sunnyvale, USA). pHi values in triplicate wells were obtained from three technical replicates and two biological replicates. A standard curve was obtained using cells suspended in loading buffer at $\mathrm{pH}$ of $6.2,6.6,7.0,7.4,7.8$ or 8.2 with $0.1 \mu \mathrm{M}$ BCECF-AM and 2 $\mu \mathrm{M}$ Nigericin. The intracellular $\mathrm{pH}$ was calculated based on the standard curve.

\section{Immunofluorescence microscopy}

Cells were settled onto poly-L-lysine treated slides, fixed in $4 \%$ formaldehyde and permeabilized with $0.3 \%$ Triton $\mathrm{X}-100$. After blocking with 3\% BSA in PBS, cells were stained with Rabbit anti-HA polyclonal (1:100, Beyotime, Shanghai, China) and rabbit anti-VP1 polyclonal (1:300) [32] primary antibodies to visualize HA-tagged protein and acidocalcisomes, respectively. As a secondary antibody, TRITC conjugated goat anti-rabbit IgG $(\mathrm{H}+\mathrm{L})$ (Invitrogen, Carlsbad, USA) was used. The mitochondrion in T. brucei was monitored by microscopy after incubation with $50 \mathrm{nM}$ Mito-Tracker Red CMXRos (Life Technologies, Carlsbad, USA) in HMI-9 for 20 min at 37 ${ }^{\circ} \mathrm{C}$, followed by washing with PBS. The cells were fixed on slides in 4\% formaldehyde and washed in PBS with 0.1 M glycine. DNA contents were stained with DAKO fluorescent mounting medium containing $50 \mathrm{ng} / \mathrm{ml}$ DAPI. Images were documented using a Zeiss Axio Imager A2m epifluorescence microscope and a Nikon N-SIM microscope.

\section{Trypanolysis assay}

Wild-type (WT) and TbVAB cKO cells were pelleted and resuspended in tetracycline-free HMI-9 medium supplemented with $10 \%(\mathrm{v} / \mathrm{v})$ FCS and incubated for $8 \mathrm{~h}$ at $37^{\circ} \mathrm{C}$. Then cells were diluted to $2 \times 10^{5}$ cells/ $\mathrm{ml}$ in HMI-9 medium and aliquoted into 48-well plates 
alongside various concentrations $(1 \%$ or $5 \%)$ of normal human serum (donated by male volunteers in our laboratory). Cells were incubated in triplicate wells at $37^{\circ} \mathrm{C}$ with $5 \% \mathrm{CO}_{2}$ and counted with a hemocytometer every 8 h. Experiments were done with three biological replicates $(n=3)$.

\section{Endocytosis assays using fluorescence microscopy and flow cytometry}

BSF cells in exponential phase were harvested by centrifugation at $1000 \times \mathrm{g}$ for $10 \mathrm{~min}$ at $4{ }^{\circ} \mathrm{C}$, washed in cold PSG and then resuspended to $5 \times 10^{6} / \mathrm{ml}$ in cold PSG with either $10 \mu \mathrm{g} / \mathrm{ml}$ DyLight 488-tomato lectin (Vector Laboratories, Burlingame, USA) or DyLight 594-tomato lectin (Vector Laboratories, Burlingame, USA), $5 \mathrm{mg} /$ ml 10,000 MW dextran Alexa Fluor 488 (Life Technologies, Carlsbad, USA) or $50 \mu \mathrm{g} / \mathrm{ml}$ transferrin Alexa Fluo 488 (Life Technologies, Carlsbad, USA) [33]. After incubation at $37{ }^{\circ} \mathrm{C}$ for series time points, the endocytosis was terminated on ice and half of the cells were pelleted and resuspended to $2.5 \times 10^{6} / \mathrm{ml}$ in cold PSG with $2 \%$ paraformaldehyde and then analyzed by flow cytometry (30,000 counts). The other half of the cells were mounted on slides and monitored by fluorescence microscopy.

\section{Statistical analysis}

Image J software [34] was used to measure the quantitative relation of proteins in western blot assays by gray scanning. Prism ${ }^{\circledR} 5.0$ software (GraphPad Software Inc) was used to graphically represent data and perform statistical analysis using an unpaired $t$-test. $P$-values of less than 0.05 were considered significant. Data are presented as the mean \pm standard deviation (SD).

\section{Results}

TbVAB is localized in multiple organelles of bloodstream form trypanosomes and essential for cell growth

To investigate the localization of vacuolar ATPase in the BSF of T. brucei, a cell line expressing YFP-tagged vacuolar ATPase subunit B in situ was generated (TbVAB::YFP). Immunoblotting using rabbit polyclonal antibodies against TbVAB showed that both the YFPtagged $T b V A B$ gene and the wild-type $T b V A B$ gene were expressed (Additional file 2: Figure S1). We incubated YFP-tagged trypanosomes with $10 \mu \mathrm{g} / \mathrm{ml}$ tomato lectin, at $37{ }^{\circ} \mathrm{C}$ for $30 \mathrm{~min}$, which are efficiently taken up and delivered to the lysosome. Fluorescence microscopy revealed multiple intracellular localizations, a few large spots adjacent to the flagellar pocket colocalized with

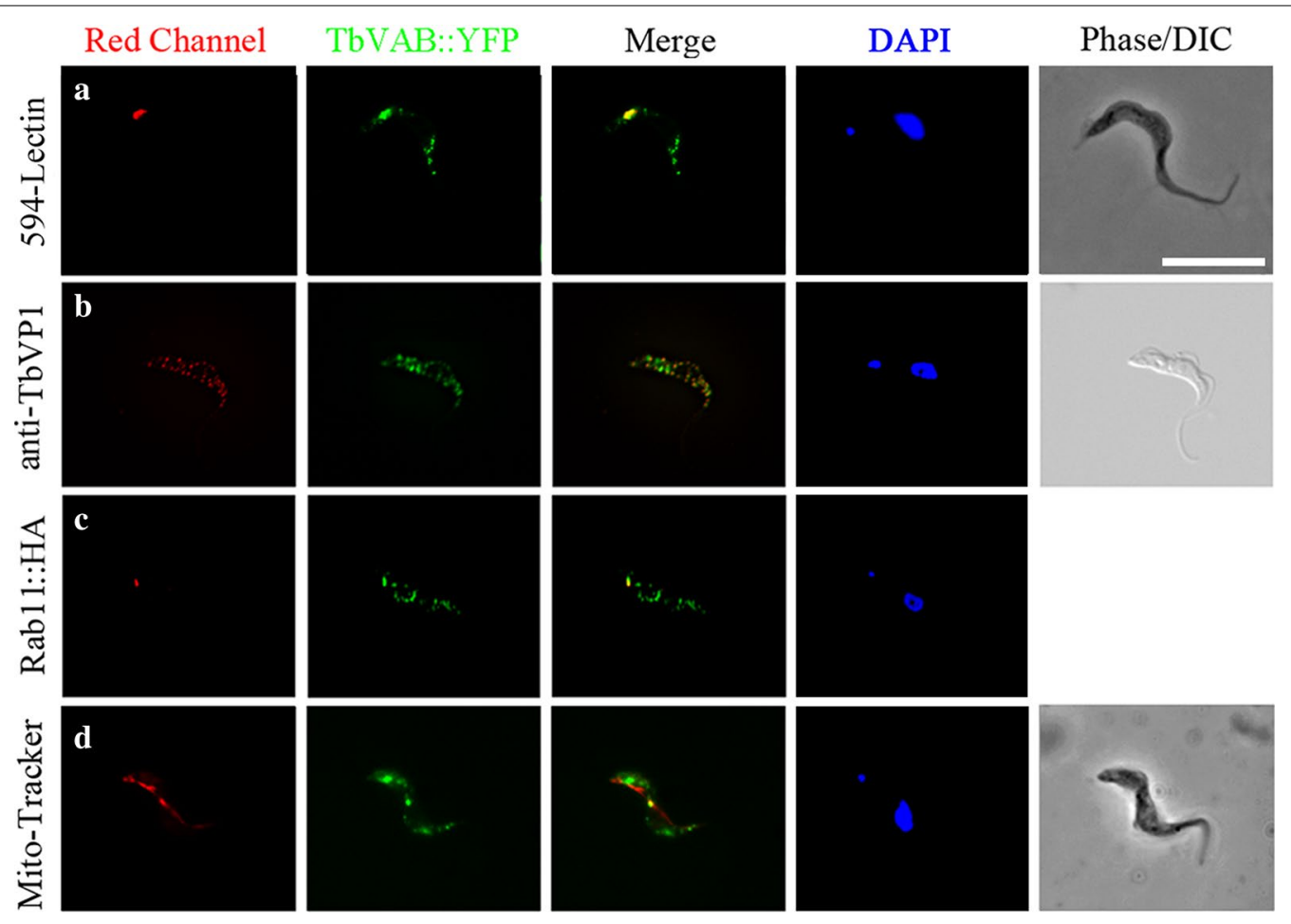

Fig. 1 TbVAB localizes to acidocalcisomes, lysosomes and endosomal vesicles in the bloodstream forms of Trypanosoma brucei. The endogenous TbVAB::YFP partially co-localized with endocytosed DyLight 594-lectin (a), the acidocalcisomes marker TbVP1 (b) and the recycling endosomal marker Rab11 (c) in BSF of T. brucei as shown by immunofluorescence microscopy. No colocalization with Mito-Tracker was observed (d). Nuclei and kinetoplasts were stained with $50 \mathrm{ng} / \mathrm{ml} \mathrm{DAPI}$. Scale-bar: $10 \mu \mathrm{m}$ 
the endocytosed 594-Lectin (Fig. 1a) while punctuated spots diffused through the cytosol colocalized with the acidocalcisomal marker TbVP1 (vacuolar proton pyrophosphatase) (Fig. 1b). Some TbVAB-positive punctuated spots were colocalized with HA-tagged Rab11, a recycling endosomal marker (Fig. 1c). Nevertheless, TbVAB was not found in the mitochondrion as defined by the Mito-Tracker dye (Fig. 1d).

To understand the function of $T b V A B$, a conditional knockout BSF cell line was generated by replacing both $T b V A B$ alleles in a tetracycline inducible $T b V A B$ expression cell line. The correct gene integrations of both TbVAB alleles were confirmed by PCR (Additional file 3: Figure S2) and the disruption of $T b V A B$ expression after tetracycline withdrawal was confirmed by immunoblotting using the rabbit polyclonal antibodies against TbVAB (Fig. 2a). TbVAB cKO BSF parasites exhibited severe growth defects at $36 \mathrm{~h}$ post-tetracycline depletion, but almost no growth defects before 24 hpd (Fig. 2a). When looking at the cell cycle stages, little was altered during the 12 to 24 hpd phase (Fig. 2b), therefore the following experiments were conducted in that same time window.
RNAi knockdown of the V-ATPase subunit A (TbVAA) in the BSF of T. brucei clones led to significant growth defects (Fig. 2c). These data, taken together with similar growth defects caused by knockdown of other V-ATPase subunits in previous studies [5-7], revealed that the integrity of the whole V-ATPase complex is essential for the BSF of T. brucei.

\section{V-ATPase depletion neutralized the acidic organelles and disturbed the intracellular pH homeostasis in BSF trypanosomes}

V-ATPase has well known activity in maintaining the acidic environment of intracellular vacuoles, such as lysosomes and also acidocalcisomes, a lysosome-related organelle, in T. brucei $[5,20]$. To confirm the specificity of depletion of $T b V A B$, the acidity of these intracellular organelles of TbVAB cKO and control cells were monitored with Acridine Orange staining. In comparison with the non-induced control cells, AO red fluorescence intensity was significantly depleted in TbVAB cKO cells at $12 \mathrm{hpd}\left(t_{(35)}=6.202, P<0.001\right)$ and $24 \mathrm{hpd}\left(t_{(35)}=\right.$ 8.465, $P<0.001$ ) (Fig. 3a, b).
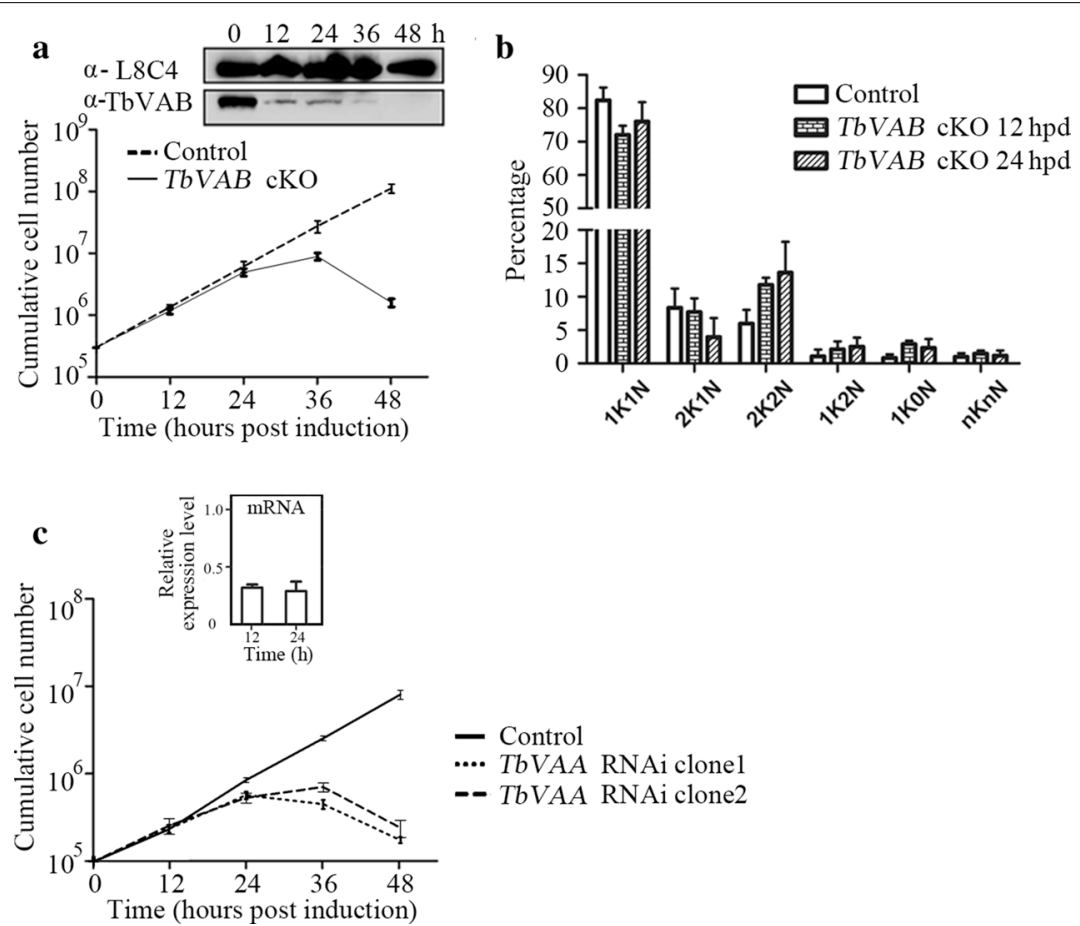

Fig. 2 Growth curves of bloodstream forms of Trypanosoma brucei after depletion of TbVAB and TbVAA. a Cumulative growth curves of the inducible conditional TbVAB knockout in T. brucei bloodstream SmOx B427 cells. The ectopically TbVAB modified cells were grown in HMI-9 (10\% FCS) with $1 \mu \mathrm{g} / \mathrm{ml}$ tetracycline and used as a control. TbVAB expression was detected by Western blot analysis with the internal loading control being monoclonal antibody L8C4 which recognizes the paraflagellar rod. $\mathbf{b}$ Analysis of kinetoplast $(\mathrm{K})$ and nucleus (N) numbers in the bloodstream form $T$. brucei after knockout of TbVAB. Kinetoplasts and nuclei of 510 cells in each group were counted after stained with DAPI. c Cumulative growth curve of the inducible knockdown of TbVAA in T. brucei bloodstream forms. Non-induced trypanosomes were used as control. The extent of TbVAA mRNA knockdown was assayed by qRT-PCR at indicated time points. The TbVAA mRNA expression from biological triplicates was shown with reference to the GAPDH gene 


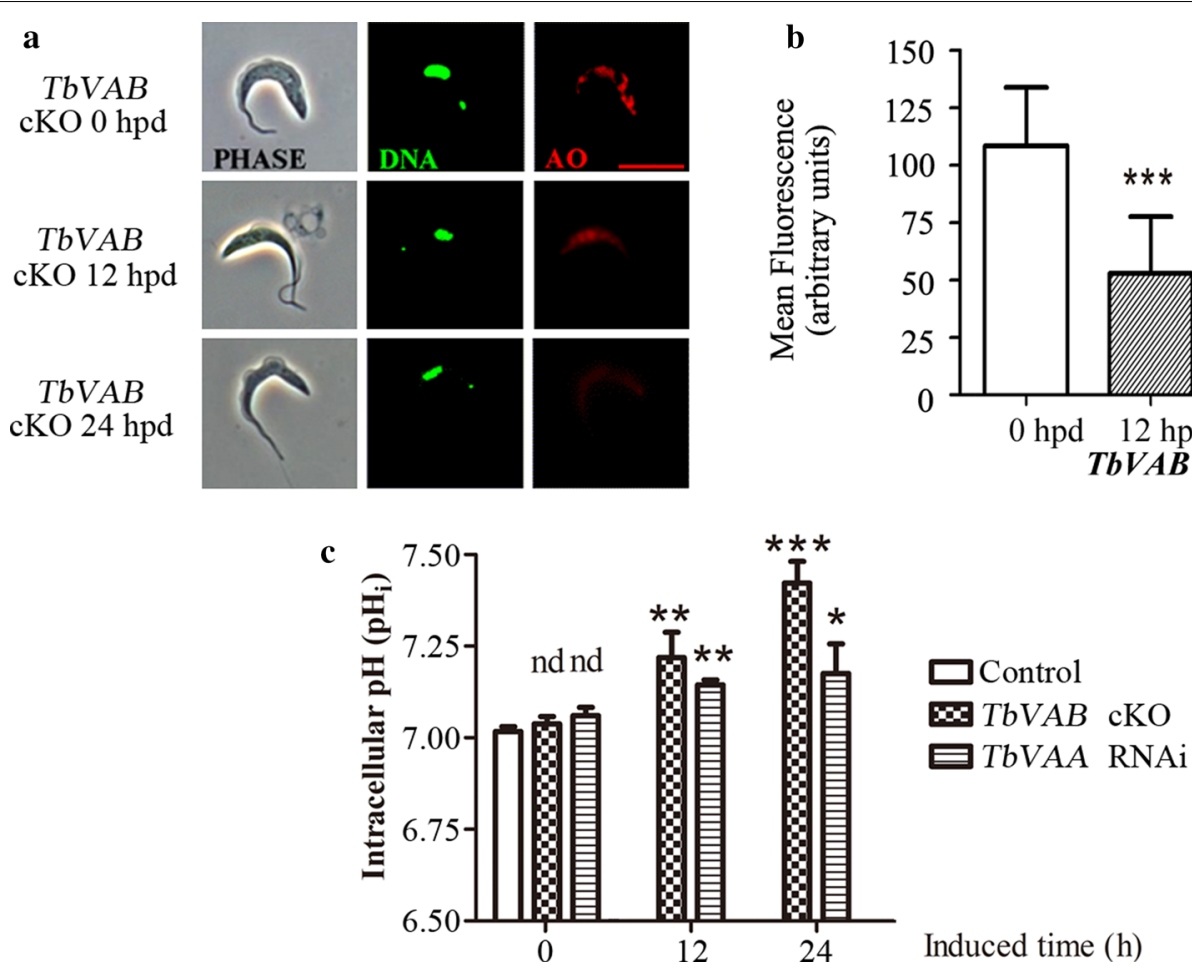

Fig. 3 TWVAA and TOVAB depletion affects vacuolar and cellular pH in bloodstream form Trypanosoma brucei. a The TbVAB cKO BSF trypanosomes were stained with $6 \mu \mathrm{M}$ acridine orange before and after $12 \mathrm{~h}$ or $24 \mathrm{~h}$ with tetracycline withdrawal and the signals were measured by fluorescence microscopy using the 590-650 nm filter channel. The DNA was monitored with the 505-550 nm filter channel. Scale-bar: $10 \mu \mathrm{m}$. b Quantitation of mean AO fluorescent intensities in cKO controls (33 cells), 12-hpd (76 cells) and 24-hpd (79 cells) TbVAB cKO cells. The unpaired t-test indicated significant differences (*** $>0.001)$ between control and TbVAB CKO cells. Data are representative of three biological replicates. $\mathbf{c} T$ The $\mathrm{pH} \mathrm{H}_{\mathrm{i}}$ of $T b V A B$ CKO and TbVAA knockdown, non-induced control and parental BSF cells were stained with BCECF-AM and measured with microplate fluorometer in triplicate wells from three technical replicates and two biological replicates. Error bars indicate the SD; ${ }^{*} P<0.05,{ }^{* *} P<0.01,{ }^{* * *} P<0.001$, nd, no change detected

The steady state intracellular $\mathrm{pH}\left(\mathrm{pH}_{\mathrm{i}}\right)$ was monitored using the cell permeable $\mathrm{pH}$ indicator BCECF-AM. The TbVAB cKO cells at 0 hpd showed a similar level of $\mathrm{pH}_{\mathrm{i}}$ to the parental cells $(7.016 \pm 0.013$ versus $7.038 \pm 0.019$, $t_{(4)}=1.580, P=0.189$ ) (Fig. 3c), whereas at $12 \mathrm{hpd}$ and 24 hpd, the $\mathrm{pH}_{\mathrm{i}}$ was increased to $7.219 \pm 0.068\left(t_{(4)}=5.017\right.$, $P=0.007)$ and $7.422 \pm 0.058\left(t_{(4)}=11.560, P<0.001\right)$, respectively (Fig. 3c). Similar phenotypes were found in TbVAA knockdown cells (Fig. 3c). Taken together, these data suggested that the depletion of $T b V A B$ or TbVAA resulted in the disruption of intracellular $\mathrm{pH}$ homeostasis in the BSF of T. brucei.

\section{Depletion of V-ATPase subunits altered endocytosis in BSF trypanosomes and reduced the sensitivity to NHS-mediated trypanolysis}

Our findings that the V-ATPase subunit TbVAB is localized to lysosomes and probably endosomes (Fig. 1) imply a possible relationship between V-ATPase and endocytic activity. To test this, fluorescence imaging and flow cytometry assays were performed using different surrogate markers: transferrin, tomato lectin and dextran. At $4{ }^{\circ} \mathrm{C}$, the $T b V A B$ cKO cells hardly bound transferrin in the flagellar pocket and were similar to the non-induced cells (Fig. 4a). When incubated with transferrin for $16 \mathrm{~min}$ at $37{ }^{\circ} \mathrm{C}$, the internalization (endocytosis) of transferrin could be clearly seen in TbVAB cKO cells at 0 hpd and were even uplifted at 24 hpd (Fig. $4 \mathrm{a}$, b). Flow cytometry assays were employed to quantify the time course of transferrin accumulation. Compared with the initial status at $0 \mathrm{hpd}$, the TbVAB cKO $24 \mathrm{hpd}$ cells took up significantly more transferrin by endocytosis $\left(2.068 \pm 0.277\right.$ fold at $\left.16 \mathrm{~min}, t_{(4)}=5.310, P=0.006\right)$ after the $37{ }^{\circ} \mathrm{C}$ incubation (Fig. 4c, d). However, no statistically significant difference in transferrin uptake was found in TbVAA KD cells (Fig. 4c, d).

At $4{ }^{\circ} \mathrm{C}$, the $T b V A B$ cKO 24 hpd cells bound tomato lectin mainly in the flagellar pocket and this was similar to the cells at 0 hpd (Fig. 5a). Intriguingly, after incubation at $37^{\circ} \mathrm{C}$ for various times, the internalization of tomato lectin was disrupted in the TbVAB cKO cells (24 hpd $v s 0$ hpd cells, dropped to $52.67 \pm 21.29 \%$ at $8 \mathrm{~min}$, 

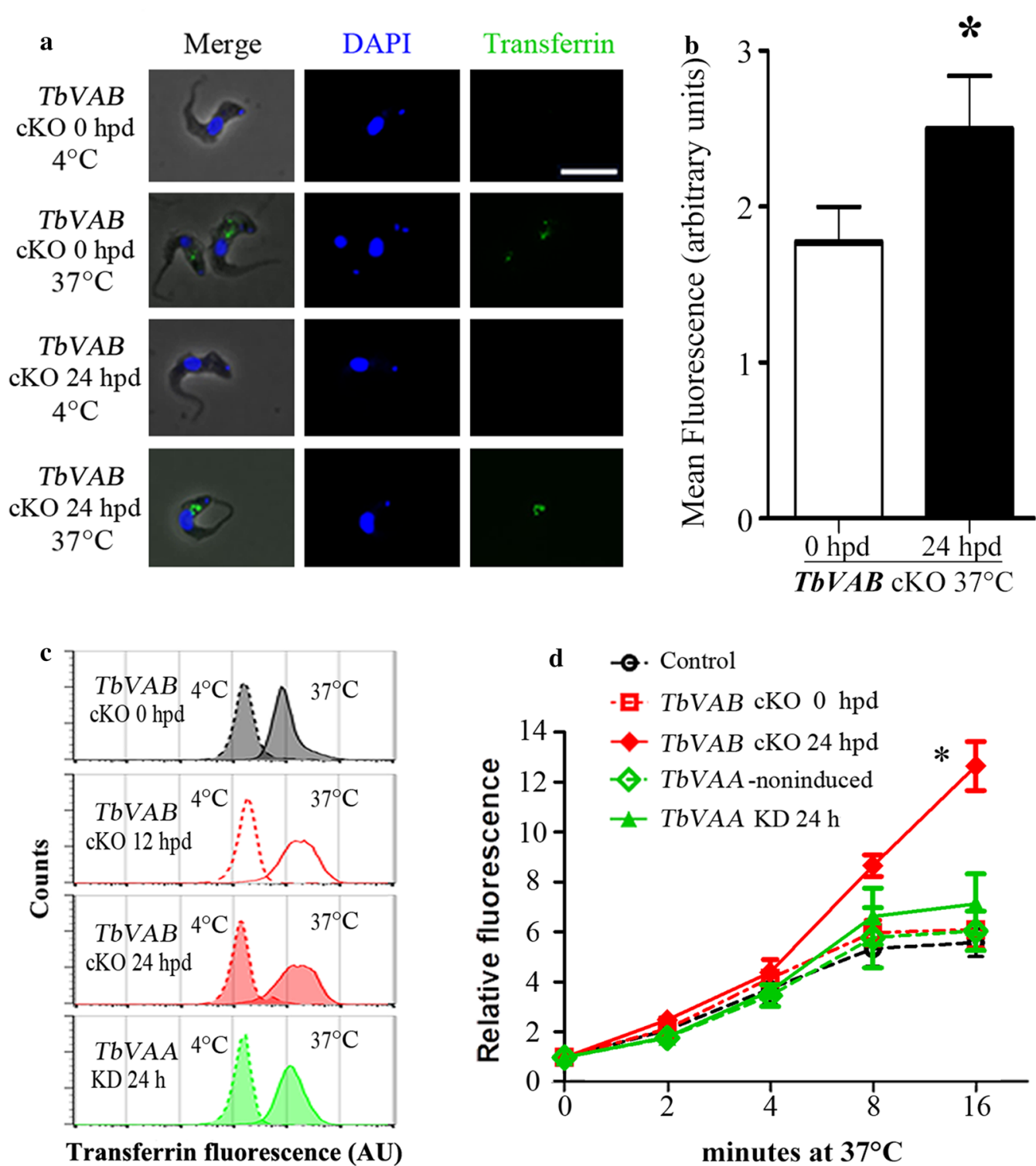

Transferrin fluorescence (AU)

Fig. 4 Effect of V-ATPase depletion on the uptake of transferrin in the bloodstream forms of Trypanosoma brucei. a Trypanosomes were allowed to endocytose transferrin Alexa Fluo 488, at the indicated temperatures for $16 \mathrm{~min}$, and were fixed and stained with DAPI. TbVAB depletion in BSF T. brucei was induced by withdrawing tetracycline for $24 \mathrm{~h}$ before the transferrin incubation. Scale-bar: $10 \mu \mathrm{m}$. b Control and TbVAB cKO $24 \mathrm{hpd}$ cells were incubated with transferrin Alexa Fluo 488 at $37^{\circ} \mathrm{C}$ for 16 min to allow transferrin uptake. Values represent the mean fluorescence for 72 cells \pm SD from three technical replicates $(n=1)$. The unpaired $t$-test indicated a significant difference $\left({ }^{*} P<0.05\right)$ between control and TbVAB cKO 24 hpd cells. c Internalization of transferrin increased after the induction of TbVAB knockout. Cells were incubated with transferrin Alexa Fluo 488 at $4{ }^{\circ} \mathrm{C}$ and then transferred to $37^{\circ} \mathrm{C}$ for 16 min to activate endocytosis. Fluorescent intensities distributions of 30,000 cells were analyzed and shown in the flow cytometry diagrams. AU, arbitrary units. $\mathbf{d}$ Flow cytometry analysis of transferrin uptake after TbVAB knockout and TbVAA knockdown. Cells were incubated with transferrin Alexa Fluo 488 at $4{ }^{\circ} \mathrm{C}$ and subsequently transferred to $37^{\circ} \mathrm{C}$ at the times indicated. Mean fluorescence intensity values of 30,000 cells were normalized against the $4^{\circ} \mathrm{C}$ incubated cells. Unpaired $t$-test analysis indicated a significant difference $(* * P<0.01)$ between TbVAB cKO 0 hpd and 24 hpd cells

$t_{(4)}=4.514, P=0.011$, or $49.31 \pm 22.57 \%$ at $16 \mathrm{~min}$, $t_{(4)}=4.225, P=0.013$; Fig. 5b-d). However, it was only slightly inhibited in the TbVAA KD cells ( $24 \mathrm{~h}$ induced $v s$ non-induced cells, dropped to $90.05 \pm 8.86 \%$ at 8 min, $t_{(4)}=1.222, P=0.289$, or $87.24 \pm 11.93 \%$ at 16 min, $t_{(4)}=1.811, P=0.144$, respectively) after the 16 min incubation (Fig. 5c, d). Neither mislocalization of lectin nor transferrin was observed, indicating no major defects in the endomembrane system morphology. To exclude the possibility that the internalization 
(See figure on next page.)

Fig. 5 Effects of V-ATPase depletion on the uptake of lectin and dextran in BSF Trypanosoma brucei. a The BSF trypanosomes were allowed to endocytose DyLight 594-tomato lectin, at the indicated temperatures for $30 \mathrm{~min}$, and were fixed and stained with DAPI. TbVAB depletion in BSF T. brucei was induced by withdrawing tetracycline for $24 \mathrm{~h}$ prior to the tomato lectin incubation. Scale-bar: $10 \mu \mathrm{m}$. b Control and TbVAB cKO $24 \mathrm{hpd}$ cells were incubated with DyLight 594 -tomato lectin at $37^{\circ} \mathrm{C}$ for $30 \mathrm{~min}$ to allow lectin uptake. Values represent the mean fluorescence for 33 cells $\pm S D$. The unpaired $t$-test indicated a significant difference $\left({ }^{*} P<0.05\right)$ between control and TbVAB cKO $24 \mathrm{hpd}$ cells. $\mathbf{c}$ Internalization of tomato lectin decreased after the induction of TbVAB knockout (CKO) and TbVAA knockdown (KD). Cells were incubated with DyLight 488-tomato lectin at $4{ }^{\circ} \mathrm{C}$ and then transferred to $37^{\circ} \mathrm{C}$ for 16 min to activate endocytosis. Fluorescent intensities distributions of 30,000 cells were analyzed. AU, arbitrary units. d, e Flow cytometry analysis of tomato lectin and dextran uptake after TbVAB knockout and TbVAA knockdown. Cells were incubated with DyLight 488-tomato lectin (d) or dextran Alexa Fluor 488 (e) at $4{ }^{\circ} \mathrm{C}$ and subsequently transferred to $37^{\circ} \mathrm{C}$ for the time indicated. Mean fluorescence intensity values of 30,000 cells were normalized against the $4^{\circ} \mathrm{C}$ incubated cells. The unpaired $t$-test analysis of lectin uptake indicated a significant difference $\left({ }^{*} P<0.05\right)$ between TbVAB CKO 0 hpd and 24 hpd cells

of tomato lectin or transferrin was caused by receptorindependent fluid-phase pinocytosis, the uptake of Dextran Alexa Fluor 488 was measured in control or V-ATPase depleted cells. As shown in Fig. 5e, no significant change in relative fluorescence was detected by measurements of dextran uptake. Taken together, the above results indicated that V-ATPase contributes to the endocytosis process in BSF trypanosomes in a receptor/cargo-dependent manner.

As the endocytosis-related function of V-ATPase depends on the specific receptor/cargo, this raises the question of whether it also influences uptake of trypanosome lytic factor (TLF). Considering that both TLF-1 and -2 contain APOL1 and haptoglobin-related protein, TLF uptake could be assessed by immunoblotting with antiAPOL1 antibodies. The uptake of TLF in TbVAB cKO 24 hpd cells was at a distinctively low level (about $30 \%$ of the 0 hpd cells' level at $8 \mathrm{hpd}$ and later undetectable at 16 or 24 hpd) (Fig. 6a). Consistent with the low uptake of TLF, we found that TbVAB cKO cells, 8 hpd before 8 or $16 \mathrm{~h}$ NHS incubation, exhibited a high resistance to either $1 \%$ or $5 \%$ NHS treatment (Fig. 6b).

\section{Discussion}

In this work we report, for the first time, the multiple localization of V-ATPase in the bloodstream forms of $T$. brucei. This feature suggests potential involvement of the complex in the function of co-localized organelles. Previous studies showed that V-ATPase mainly contributes to $\mathrm{H}^{+}$gradient generation in acidocalcisomes and acidification in other vesicles as well as $\mathrm{pH}_{\mathrm{i}}$ regulation and $\mathrm{Ca}^{2+}$ homeostasis in T. brucei $[5,22,23]$. It has also been reported that V-ATPase contributes to the action of other membrane pumps/channels, such as $\mathrm{Ca}^{2+} / \mathrm{H}^{+}$exchangers, $\mathrm{Na}^{+} / \mathrm{H}^{+}$exchangers, $\mathrm{Ca}^{2+}$ transporters, $\mathrm{Zn}^{2+}$ transporters, pyruvate transporters and other $\mathrm{H}^{+}$-ATPase(s) in T. brucei $[19,22,35]$. Therefore, the multiple functions of V-ATPase in T. brucei may reflect its position as a vital node in the ion distribution network. In our hands, by eliminating potential nonspecific interference by chemical compound inhibitors, we provided direct evidence of vacuolar and cytoplasmic alkalinization in TbVAB depleted BSF of T. brucei. T. brucei maintains a constant $\mathrm{pH}_{\mathrm{i}}$ over a narrow range of extracellular $\mathrm{pH}$ [36], which we measured as a $\mathrm{pH}_{\mathrm{i}}$ of $7.016 \pm 0.013$. This value is in a good agreement with some studies [37-39], but lower than others $[22,40]$. The discrepancy in $\mathrm{pH}_{\mathrm{i}}$ values might be due to different choices of $\mathrm{pH}$ reporters or probes. We suspect that these abnormalities in the $\mathrm{pH}$ homeostasis in the cytoplasm of V-ATPase ablated BSF of $T$. brucei might be due to abnormal proton efflux activity occurring as a result of the coordinated effects of V-ATPase and membrane pumps.

The localization of T. brucei V-ATPase in lysosomes and, probably endosomes, suggests the potential involvement of V-ATPase in endocytosis linked protein trafficking. We showed that endocytosis in TbVAB depleted BSF was linked to a significant decrease in lectin and TLF uptake. Hence, we consider that V-ATPase may possibly act as a specific endocytosis regulator in the BSF T. brucei. In contrast to lectin and TLF uptake, endocytosed transferrin was elevated in $T b V A B$ depleted cells and this was consistent with another study using V-ATPase subunit F knockdown in T. brucei [5]. In fact, selective endocytosis, induced by endocytic protein silencing in T. brucei, is a common phenomenon such as in ATG24 silencing which impairs the uptake of transferrin but not lectin [41]. Ablation of TbRab11 has less of an effect on trafficking of GPI anchored proteins but strongly influenced recycling of transmembrane proteins [42]. Taken together these data suggest that, in the BSF T. brucei, V-ATPase may be a key component in endocytosis and determine specific cargo/receptor-dependent interactions.

The endocytic process and endosomal sorting regulatory mechanisms have been well studied in T. brucei [43, 44]. Other studies, such as effects of silencing endocytosis regulators on cell morphology, may help to understand the possible mechanisms that link V-ATPase to the endocytic process. By possessing a subpellicular microtubule cytoskeleton, T. brucei restricts endocytosis 


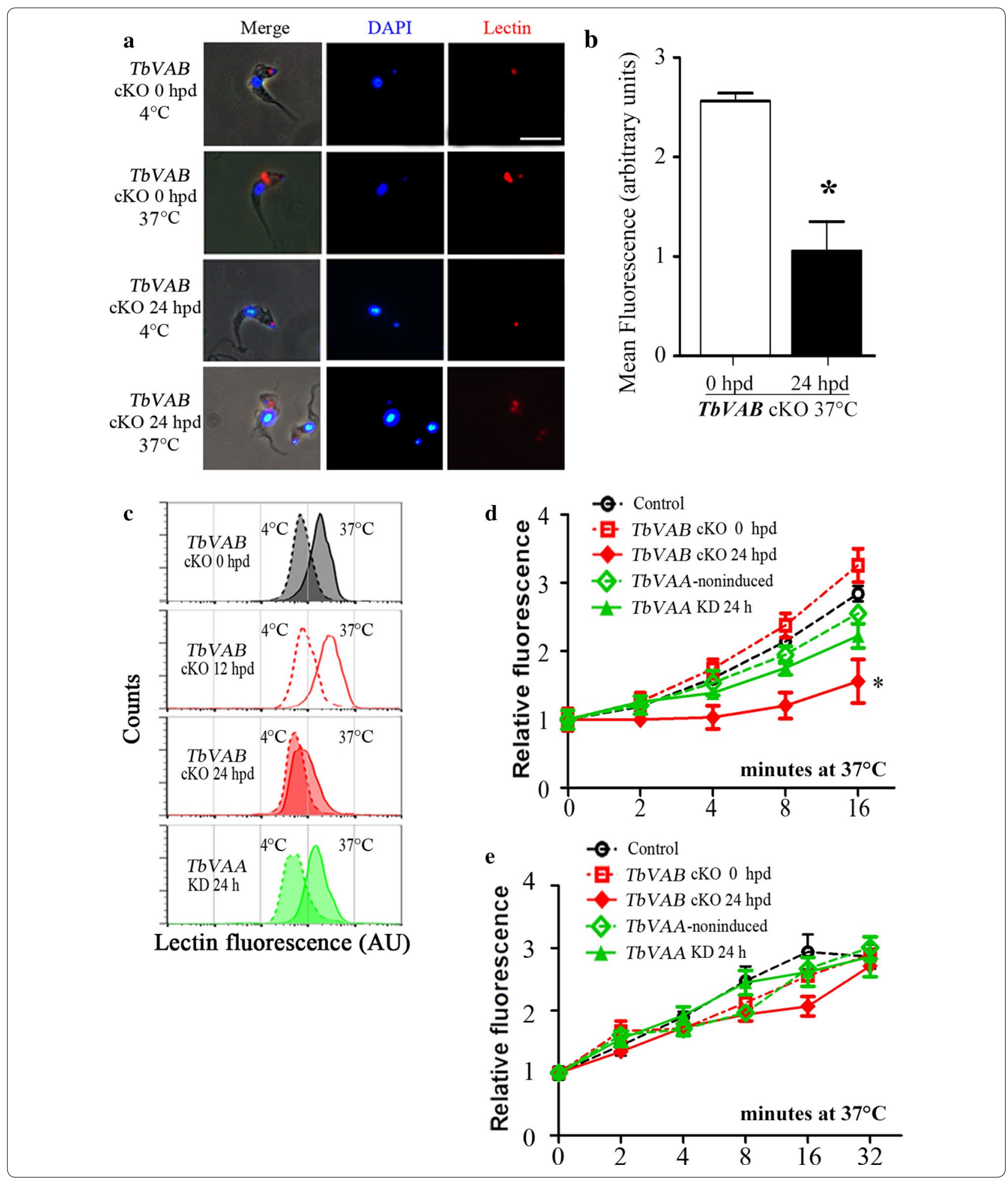

and exocytosis to the flagellar pocket (FP) [45]. Endocytic mutant phenotypes such as FP enlargement can be observed in examples like the 'BigEye' trypanosome, caused by ablation of clathrin [46]. Interestingly, however,
FP enlargement was only very occasionally observed in TbVAB depleted BSF T. brucei suggesting that V-ATPase might not affect clathrin function. Also endocytosed lectin dramatically decreased while the flagellar pocket 


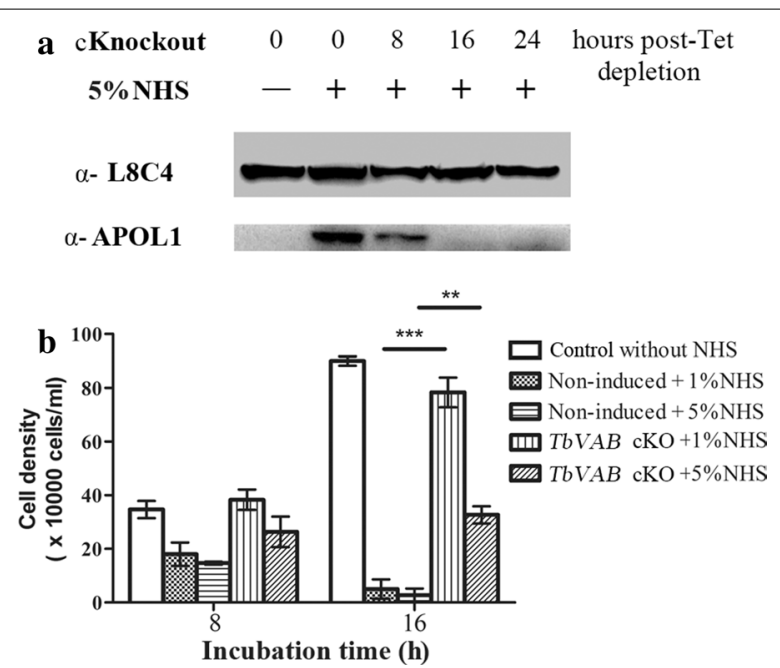

Fig. 6 Depletion of TbVAB renders trypanosome cells less sensitive to trypanolysis by normal human serum. a Western blot analysis detecting endocytosed TLF shows relative uptake in non-induced and TbVAB depleted cells after incubation with $5 \% \mathrm{NHS}$ at indicated time points. L8C 4 was used as a constitutive control. b Trypanosome cell density was measured after incubation with normal human serum for $8 \mathrm{~h}$ or $16 \mathrm{~h}$. Induced TbVAB depletion cells and non-induced cells were subjected to incubation with NHS. Error bars represent the standard deviation of biological triplicates. The unpaired $t$-test indicated significant differences $\left({ }^{* *} P<0.01,{ }^{* * *} P<0.001\right)$ between non-induced and $C K O$ induced cells

lectin was retained in $T b V A B$ depletion suggesting suppression of pNAL-glycoprotein, the lectin receptor involved in endocystosis. We also suggest that V-ATPase activity might play a role in actin-dependent endocytosis as decreased lectin uptake was also found in actin ablated BSF of T. brucei [47]. Indeed, such links between actin and V-ATPase have been revealed in insect and mammalian cells [48, 49]. However, as endocytosed lectin decreased and had a distinctly non-lysosomal localization in Rab7 ablated BSF cells [50], the role of V-ATPase in regulating endocytosis probably differs from the Rab7 associated mechanism. Despite the diversity of endocytic defects, both actin and Rab7 ablated trypanosomes show significant resistance to NHS lysis $[47,50]$ and this is in agreement with our findings for $T b V A B$.

The trypanolysis caused by NHS is a serial process of initial TLF uptake in the flagellar pocket, progressive acidification in endosomal vesicles and formation of pores in the membrane. Theoretically, any barrier in the process described above will prevent the trypanolysis of trypanosomes. The SRA protein has evolved as a barrier to pore formation by APOL1 in T. brucei rhodesiense conferring human serum resistance [3]. Endosomal alkalinization, such as chloroquine treatment, can block trypanolysis by TLF in T. brucei [51]. Also the rate of uptake of TLF in T. brucei directly impacts NHS sensitivity in surface receptor TbHpHbR defective cells [52] and $T$. brucei 427-800 cells [51]. In the case of V-ATPase knockdown trypanosomes, previous studies have revealed that raised endosomal $\mathrm{pH}$ caused by the knockdown may contribute to the reduced sensitivity to NHS-mediated trypanolysis [5]. Here, we have added further important evidence that the defects in uptake of TLF, in $T b V A B$ depleted BSF of T. brucei, may also bolster the resistance to NHS lysis, as it occurs prior to endosomal alkalinization. Considering the relationship between $\mathrm{pH}_{\mathrm{i}} /$ endosomal acidity and TLF uptake, treatment with chloroquine alkalinizes endosomes but causes accumulation of intracellular TLF [51, 53], suggesting that the acidic $\mathrm{pH}$ in the endosomes is not correlated with the uptake of TLF. Additionally, endocytosed APOL1 could lyse trypanosomes by utilizing a novel pathway of mitochondrial membrane permeabilization [54]. Therefore, a single blockage by endosomal alkalinization may not be sufficient for establishing complete TLF resistance, which is suggested by our identification of a relationship between endocytosis and V-ATPase in the BSF of T. brucei.

Differences in endocytic activity using different cargoes after ablation of V-ATPase subunits may be due to corresponding receptor(s) that mediate the endocytosis pathway in T. brucei. Lectin binds efficiently to membrane pNAL-glycoproteins [55] whilst the majority of TLF-1 binds to the GPI-anchored surface receptor TbHpHbR [56]. In the case of TLF-2, it has been proposed that TLF-2 enters trypanosomes by binding to the VSG coat and utilizing high-mannose containing residues in the binding interaction [57]. The lipoprotein receptor pathway and fluid-phase pathway may also make a minor contribution to the uptake of TLF-1/2 [58]. Our results cannot be used to distinguish the specific proportion of endocytosed TLF-1 or -2 in endocytosis-defective V-ATPase depleted trypanosomes.

\section{Conclusions}

This study demonstrates, for the first time to our knowledge, that the V-ATPase subunit B (TbVAB) is localized in acidocalcisomes, lysosomes and probably endosomes of the bloodstream form T. brucei. V-ATPase is a critical proton pump complex in the endomembrane system of $T$. brucei bloodstream forms, which functions in the acidification of organelles, $\mathrm{pH}_{\mathrm{i}}$ homeostasis, and endocytic regulation. $T b V A B$ depleted bloodstream forms of T. brucei increased their endocytic uptake of transferrin and decreased their uptake of lectin and TLF, resulting in a reduced sensitivity to trypanolysis by normal human serum. Suppression of V-ATPase activity could potentially benefit the evolution of trypanosomes by improving trypanolytic tolerance. This study provides a deeper 
interpretation of the roles of V-ATPase in endocytic activity in T. brucei BSF physiology.

\section{Supplementary information}

Supplementary information accompanies this paper at https://doi. org/10.1186/s13071-020-04068-4.

Additional file 1: Table S1. Primers used for PCR in this study.

Additional file 2: Figure S1. Immunoblotting of BSF and PCF of Trypanosoma brucei probed with rabbit polyclonal antibodies against TbVAB. TbVAB was detected by resolving whole cell lysates samples of bloodstream forms (SmOx B427) and procyclic forms (SmOx PAnTat 1.1) of T. brucei on 10\% Tris-SDS-PAGE gels followed by western blotting probed with rabbit anti-TbVAB polyclonal antibodies. TbVAB::YFP and TbVAB were detected by resolving whole cell lysates sample of in situ monoallelic TbVAB::YFP labeled bloodstream forms of T. brucei with rabbit anti-TbVAB polyclonal antibodies. M, molecular mass markers.

Additional file 3: Figure S2. Validation of the TbVAB knockout and homologous recombination strategy for the deletion of TbVAB. The gel shows the PCR assays. PCR using primers targeting UTR flanking sequences and gene internal sequences demonstrated that the original alleles were disrupted (line 3). For single TbVAB allele replacement by homologous recombination, the TbVAB gene locus was initially disrupted by integration of a linear fragment containing TbVAB UTR and a hygromycin gene. After obtaining a single allele replaced population, an additional tetracycline inducible overexpression TbVAB fragment was integrated into the genome and followed by the integration of a linear fragment containing TbVAB UTR and a neomycin gene. PARP, procyclic acidic repetitive protein promoter. T7RNAP, bacteriophage T7 RNA polymerase. ALD, aldolase derived UTRs. ACT, actin derived UTRs. Tetr, Tet repressor. HYG, hygromycin phosphotransferase gene. NEO, neomycin phosphotransferase gene.

\section{Abbreviations}

AO: acridine orange; APOL1: apolipoprotein L1; BCECF-AM: 2', 7'-bis (2-carboxyethyl)-5, 6-carboxyfluorescein acetoxymethyl ester; BSF: bloodstream forms; cKO: conditional knockout; hpd: hours post-tetracycline depletion; KD: RNAi knockdown; NHS: normal human serum; PCF: procyclic form; $\mathrm{pH}_{\mathrm{i}}$ : intracellular pH; TLF: trypanosome lytic factors; TbVAA: V-ATPase subunit A; TbVAB: V-ATPase subunit B; V-ATPase: vacuolar $\mathrm{H}^{+}$-ATPase.

\section{Acknowledgements}

We thank Professor Cynthia He from the National University of Singapore, Singapore and Professor Keith Gull from the University of Oxford, UK for providing the anti-VP1 antibody (generated by Professor Roberto Docampo) and the L8C4 antibody.

\section{Authors' contributions}

ZSX, DHL and ZRL designed this work and XZS carried out the experiments. ZSX, DHL, ZRL, FJL and GH analyzed the data. ZSX wrote the draft of the manuscript, DHL, FJL, ZRL and GH improved all the versions. All authors approved the final version of the manuscript.

\section{Funding}

This work was supported by grants from the National Natural Science Foundation of China (31672276 and 31720103918) to ZRL and the Natural Science Foundation of Guangdong Province (2016A030306048) to DHL.

\section{Availability of data and materials}

All relevant information has been included in the manuscript and its additional files. Data analyzed in this study are available from the corresponding author upon reasonable request.

\section{Ethics approval and consent to participate}

This study was approved by the Medical Science Ethical Committee and the Laboratory Animal Use and Care Committee of Sun Yat-Sen University under license No. 31672276. All volunteer participants were informed about the objectives of this study before blood donation. Four- to five-month-old female
New Zealand rabbits used in this study were purchased from the Guangdong medical laboratory animal center. All animals were housed under specific pathogen-free condition according to the National Institutes of Health on animal care and the ethical guidelines.

\section{Consent for publication}

Not applicable.

\section{Competing interests}

The authors declare that they have no competing of interests.

\section{Author details}

${ }^{1}$ Center for Parasitic Organisms, State Key Laboratory of Biocontrol, School of Life Sciences, and Key Laboratory of Tropical Disease Control (Sun Yat-Sen University), Ministry of Education, Sun Yat-Sen University, Guangzhou 510275, The People's Republic of China. ${ }^{2}$ Department of Biological Sciences, National University of Singapore, Singapore 11754, Singapore. ${ }^{3}$ Biomedical Research Centre and Ecosystems and Environment Research Centre, School of Science, Engineering and Environment, University of Salford, Salford M5 4WT, UK.

Received: 24 December 2019 Accepted: 9 April 2020

Published online: 25 April 2020

\section{References}

1. Kennedy PGE. Update on human African trypanosomiasis (sleeping sickness). J Neurol. 2009;266:2334-7.

2. Engstler M, Thilo L, Weise F, Grünfelder CG, Schwarz H, Boshart M, Overath P. Kinetics of endocytosis and recycling of the GPI-anchored variant surface glycoprotein in Trypanosoma brucei. J Cell Sci. 2004;117:1105-15.

3. Xong HV, Vanhamme L, Chamekh M, Chimfwembe CE, Van Den Abbeele J, Pays A, et al. A VSG expression site-associated gene confers resistance to human serum in Trypanosoma rhodesiense. Cell. 1998;95:839-46.

4. Capewell P, Clucas C, DeJesus E, Kieft R, Hajduk S, Veitch N, et al. The TgsGP gene is essential for resistance to human serum in Trypanosoma brucei gambiense. PLoS Pathog. 2013;9:e1003686.

5. Lecordier L, Uzureau P, Tebabi P, Perez-Morga D, Nolan D, Schumann-Burkard G, et al. Identification of Trypanosoma brucei components involved in trypanolysis by normal human serum. Mol Microbiol. 2014;94:625-36.

6. Currier RB, Cooper A, Burrell-Saward H, Macleod A, Alsford S. Decoding the network of Trypanosoma brucei proteins that determines sensitivity to apolipoprotein-L1. PLoS Pathog. 2008;14:e1006855.

7. Baker N, Hamilton G, Wilkes JM, Hutchinson S, Barrett MP, Horn D. Vacuolar ATPase depletion affects mitochondrial ATPase function, kinetoplast dependency, and drug sensitivity in trypanosomes. Proc Natl Acad Sci USA. 2015;112:9112-7.

8. Mellman I, Fuchs R, Helenius A. Acidification of the endocytic and exocytic pathways. Annu Rev Biochem. 1986;55:663-700.

9. Marshansky V, Futai M. The $\mathrm{V}$-type $\mathrm{H}^{+}$-ATPase in vesicular trafficking: targeting, regulation and function. Curr Opin Cell Biol. 2008;20:415-26.

10. Nelson N, Harvey WR. Vacuolar and plasma membrane proton-adenosinetriphosphatases. Physiol Rev. 1999;79:361-85.

11. Kurashima K, Yu FH, Cabado AG, Szabo EZ, Grinstein S, Orlowski J. Identification of sites required for down-regulation of $\mathrm{Na}^{+} / \mathrm{H}^{+}$exchanger NHE3 activity by CAMP-dependent protein kinase phosphorylation-dependent and-independent mechanisms. J Biol Chem. 1997;272:28672-9.

12. Diakov TT, Kane PM. Regulation of vacuolar proton-translocating ATPase activity and assembly by extracellular pH. J Biol Chem. 2010;285:23771-8.

13. Nelson $\mathrm{H}$, Nelson N. Disruption of genes encoding subunits of yeast vacuolar $\mathrm{H}^{+}$-ATPase causes conditional lethality. Proc Natl Acad Sci USA. 1990;87:3503-7.

14. Sautin YY, Lu M, Gaugler A, Zhang L, Gluck SL. Phosphatidylinositol 3-kinase-mediated effects of glucose on vacuolar $\mathrm{H}^{+}$-ATPase assembly, translocation, and acidification of intracellular compartments in renal epithelial cells. Mol Cell Biol. 2005;25:575-9.

15. Clague MJ, Urbé S, Aniento F, Gruenberg J. Vacuolar ATPase activity is required for endosomal carrier vesicle formation. J Biol Chem. 1994;269:21-4. 
16. Dettmer J, Hong-Hermesdorf A, Stierhof YD, Schumacher K. Vacuolar $\mathrm{H}^{+}$-ATPase activity is required for endocytic and secretory trafficking in Arabidopsis. Plant Cell. 2006;18:715-30.

17. Matsuoka K, Higuchi T, Maeshima M, Nakamura K. A vacuolar-type $\mathrm{H}^{+}$-ATPase in a nonvacuolar organelle is required for the sorting of soluble vacuolar protein precursors in tobacco cells. Plant Cell. 1997;9:533-46

18. Tawfeek HA, Abou-Samra AB. Important role for the $\mathrm{V}$-type $\mathrm{H}^{+}$-ATPase and the Golgi apparatus in the recycling of PTH/PTHrP receptor. Am J Physiol-Endoc M. 2004;286:704-10.

19. Huang G, Ulrich PN, Storey M, Johnson D, Tischer J, Tovar JA, et al. Proteomic analysis of the acidocalcisome, an organelle conserved from bacteria to human cells. PLoS Pathog. 2014;10:e1004555.

20. Li FJ, He CY. Acidocalcisome is required for autophagy in Trypanosoma brucei. Autophagy. 2014;10:1978-88.

21. Bowman BJ, McCall ME, Baertsch R, Bowman EJ. A model for the proteolipid ring and bafilomycin/concanamycin-binding site in the vacuolar ATPase of Neurospora crassa. J Biol Chem. 2006;281:31885-93.

22. Vanderheyden N, Wong J, Docampo R. A pyruvate-proton symport and an $\mathrm{H}+$-ATPase regulate the intracellular $\mathrm{pH}$ of Trypanosoma brucei at different stages of its life cycle. Biochem J. 2000;346:53-62.

23. Vercesi AE, Moreno SN, Docampo R. $\mathrm{Ca}^{2+} / \mathrm{H}^{+}$exchange in acidic vacuoles of Trypanosoma brucei. Biochem J. 1994;304:227-33.

24. Poon SK, Peacock L, Gibson W, Gull K, Kelly S. A modular and optimized single marker system for generating Trypanosoma brucei cell lines expressing T7 RNA polymerase and the tetracycline repressor. Open Biol. 2012;2:110037.

25. Burkard G, Fragoso CM, Roditi I. Highly efficient stable transformation of bloodstream forms of Trypanosoma brucei. Mol Biochem Parasitol. 2007;153:220-3.

26. Alsford S, Horn D. Single-locus targeting constructs for reliable regulated RNAi and transgene expression in Trypanosoma brucei. Mol Biochem Parasitol. 2008;161:76-9.

27. Wickstead B, Ersfeld K, Gull K. Targeting of a tetracycline-inducible expression system to the transcriptionally silent minichromosomes of Trypanosoma brucei. Mol Biochem Parasitol. 2002;125:211-6.

28. Wirtz E, Leal S, Ochatt C, Cross GA. A tightly regulated inducible expression system for conditional gene knock-outs and dominant-negative genetics in Trypanosoma brucei. Mol Biochem Parasitol. 1999;99:89-101.

29. Gabernet-Castello C, Dubois KN, Nimmo C, Field MC. Rab11 function in Trypanosoma brucei: identification of conserved and novel interaction partners. Eukaryotic Cell. 2011;10:1082-94.

30. Kelly S, Reed J, Kramer S, Ellis L, Webb H, Sunter J, et al. Functional genomics in Trypanosoma brucei: a collection of vectors for the expression of tagged proteins from endogenous and ectopic gene loci. Mol Biochem Parasitol. 2007;154:103-9.

31. Kohl L, Sherwin T, Gull K. Assembly of the paraflagellar rod and the flagellum attachment zone complex during the Trypanosoma brucei cell cycle. J Eukaryotic Microbiol. 1999;46:105-9.

32. Lemercier G, Dutoya S, Luo S, Ruiz FA, Rodrigues CO, Baltz T, et al. A vacuolar-type $\mathrm{H}^{+}$-pyrophosphatase governs maintenance of functional acidocalcisomes and growth of the insect and mammalian forms of Trypanosoma brucei. J Biol Chem. 2002;277:37369-76.

33. Cheung JLY, Wand NV, Ooi C-P, Ridewood S, Wheeler RJ, Rudenko G. Blocking synthesis of the variant surface glycoprotein coat in Trypanosoma brucei leads to an increase in macrophage phagocytosis due to reduced clearance of surface coat antibodies. PLoS Pathog. 2016;12:e1006023.

34. Schneider CA, Rasband WS, Eliceiri KW. Nih image to imagej: 25 years of image analysis. Nat Methods. 2012;9:671-5.

35. Docampo R, Huang G. Calcium signaling in trypanosomatid parasites. Cell Calcium. 2015;57:194-202.

36. Fraser-L'Hostis C, Defrise-Quertain F, Coral D, Deshusses J. Regulation of the intracellular $\mathrm{pH}$ in the protozoan parasite Trypanosoma brucei brucei. Biol Chem. 1997;378:1039-46.

37. Thissen JA, Wang CC. Maintenance of internal $\mathrm{pH}$ and an electrochemical gradient in Trypanosoma brucei. Exp Parasitol. 1991;72:243-51.

38. Ruben L, Hutchinson A, Moehlman J. Calcium homeostasis in Trypanosoma brucei. Identification of a pH-sensitive non-mitochondrial calcium pool. J Biol Chem. 1991;266:24351-8.

39. Nolan DP, Voorheis HP. Hydrogen ion gradients across the mitochondrial, endosomal and plasma membranes in bloodstream forms of
Trypanosoma brucei: solving the three-compartment problem. Eur J Biochem. 2000;267:4601-14.

40. Scott DA, Moreno SN, Docampo R. Ca ${ }^{2+}$ storage in Trypanosoma brucei: the influence of cytoplasmic $\mathrm{pH}$ and importance of vacuolar acidity. Biochem J. 1995;310:789-94.

41. Ana B, Eva R, Rigden DJ, Patrick VDS, Courtoy PJ, Michels PAM. ATG24 represses autophagy and differentiation and is essential for homeostasy of the flagellar pocket in Trypanosoma brucei. PLoS ONE. 2015;10:e0130365.

42. Umaer K, Bush PJ, Bangs JD. Rab11 mediates selective recycling and endocytic trafficking in Trypanosoma brucei. Traffic. 2018;19:406-20.

43. Morgan GW, Hall BS, Denny PW, Field MC, Carrington M. The endocytic apparatus of the kinetoplastida. Part II: machinery and components of the system. Trends Parasitol. 2002;18:540-6.

44. Quintana JF, Pino RCD, Yamada K, Zhang N, Field MC. Adaptation and therapeutic exploitation of the plasma membrane of African trypanosomes. Genes. 2018;9:368.

45. Field MC, Carrington M. The trypanosome flagellar pocket. Nat Rev Microbiol. 2009;7:775-86

46. Allen CL, Goulding D, Field MC. Clathrin-mediated endocytosis is essential in Trypanosoma brucei. EMBO J. 2003;22:4991-5002.

47. García-Salcedo JA, Pérez-Morga D, Gijón P, Dilbeck V, Pays E, Nolan DP. A differential role for actin during the life cycle of Trypanosoma brucei. EMBO J. 2004:23:780-9.

48. Holliday LS, Lu M, Lee BS, Nelson RD, Solivan S, Zhang L, et al. The aminoterminal domain of the $B$ subunit of vacuolar $\mathrm{H}^{+}$-ATPase contains a filamentous actin binding site. J Biol Chem. 2000;275:32331-7.

49. Vitavska O, Merzendorfer H, Wieczorek H. The V-ATPase subunit C binds to polymeric F-actin as well as to monomeric G-actin and induces crosslinking of actin filaments. J Biol Chem. 2005;280:1070-6.

50. Silverman JS, Schwartz KJ, Hajduk SL, Bangs JD. Late endosomal Rab7 regulates lysosomal trafficking of endocytic but not biosynthetic cargo in Trypanosoma brucei. Mol Microbiol. 2011:82:664-78.

51. Faulkner SD, Oli MW, Kieft R, Cotlin L, Widener J, Shiflett A, et al. In vitro generation of human high-density-lipoprotein-resistant Trypanosoma brucei brucei. Eukaryotic Cell. 2006;5:1276-86.

52. Uzureau P, Uzureau S, Lecordier L, Fontaine F, Tebabi P, Homble F, et al. Mechanism of Trypanosoma brucei gambiense resistance to human serum. Nature. 2013;501:430-4.

53. Shimamura M, Hager KM, Hajduk SL. The lysosomal targeting and intracellular metabolism of trypanosome lytic factor by Trypanosoma brucei brucei. Mol Biochem Parasitol. 2001:115:227-37.

54. Vanwalleghem G, Fontaine F, Lecordier L, Tebabi P, Klewe K, Nolan DP, et al. Coupling of Iysosomal and mitochondrial membrane permeabilization in trypanolysis by APOL1. Nat Commun. 2015;6:8078.

55. Nolan DP, Geuskens M, Pays E. N-linked glycans containing linear poly$\mathrm{N}$-acetyllactosamine as sorting signals in endocytosis in Trypanosoma brucei. Curr Biol. 1999;9:1169-72.

56. Vanhollebeke B, De Muylder G, Nielsen MJ, Pays A, Tebabi P, Dieu M, et al. A haptoglobin-hemoglobin receptor conveys innate immunity to Trypanosoma brucei in humans. Science. 2008;320:677-81.

57. Vanhollebeke B, Pays E. The trypanolytic factor of human serum: many ways to enter the parasite, a single way to kill. Mol Microbiol. 2010;76:806-14.

58. Green HP, Del Pilar Molina Portela M, St Jean EN, Lugli EB, Raper J. Evidence for a Trypanosoma brucei lipoprotein scavenger receptor. J Biol Chem. 2003;278:422-7.

\section{Publisher's Note}

Springer Nature remains neutral with regard to jurisdictional claims in published maps and institutional affiliations. 